\title{
Role of Education in Development in and after the Transitional Period in Kosovo
}

\author{
Prof. Dr. Vjollca Dibra
}

\author{
Prishtina, March 2015, Professor, Faculty of Education, "Hasan Prishtina" Public University
} dibravjollca@gmail.com

\section{Doi:10.5901/jesr.2015.v5n1s1p143}

\begin{abstract}
The topic of the paper is focused on the education condition, in all its levels (preschool, elementary, high school, higher education and post-university studies), after the last war in Kosovo, as well as after transition period. There will be analyzed two key education functions, as basis of development: General education, as a concept of personality, and Professional skills based on contemporary trends of social, economical and technological development.Following the introduction section, where the methodology and structure of the paper will be presented; the paper will put its emphasize on the state of education, restructuring and reformatting of the education system, based on the new world expertise of the field, and also the paper will examine direct general social and economical indicators. The article will be closed by conclusion section, where conclusions and suggestions based on paper research study will be presented, in order to help the improvement of the education system of the country.
\end{abstract}

Keywords: Role, Education, Development, Transitional Period, Kosovo

\section{Introduction}

There is no doubt that social activity identified by notion education, is one of most important events. With implications for many plans, especially with specific role and weight in the development of a society or of a country, education therefore has found primary treatment. Perhaps this phenomenon has spread from the first steps of awareness of humanity, in a cultivated form comes to us from antiquity of the Far East, Near and the Middle East extending everywhere.

Without claiming to treat historical aspect of education development, the prism of my interest is focused on its role during these fifteen years in Kosovo, seen in the transitory phase and afterwards. This way of observation takes character of a non-monograph panoramic presentation because the factors are subject to specific circumstances.

However, when we talk about education in Kosovo, a look becomes inevitable, even if it is short, to prior development. As any other activity, the education has an interdependence position with concrete historical and social circumstances of Albanian society development. We just need to remind ourselves of opening of the first Albanian school (Korçë, 7 March 1887), the Congress of Albanian alphabet (Manastir, 14-22 November 1908) and University of Prishtina (15 February 1970).

I mentioned these educational nodes that come as a result of the work of early Albanian intellectuals and especially the ranks of the Renaissance who were moulded with European ideas of the Enlightenment. It is no coincidence that, like the main figure of renaissance, the writer Naim Frasheri (1846 - 1900) had made the monogram formula "And only light of knowledge forward will lead us"!

If, after periods of centuries of oppression, after eagerness for education and knowledge, a light appeared in the horizon of 1970, it suddenly, after two decades (in 1990) almost extinguished, when the Serbian regime with abolition of the autonomy of Kosovo practically suppressed the Albanian education.

It is already known that it however survived, using clandestine forms of organization and in almost impossible circumstances. The strong will of for education encouraged the education employees that even in war circumstances find ways to keep it alive.

\section{The First Years After the Last War}

There is no doubt that in an organized society with state structure, there are government bodies that can take the decision-making role in the development plan of the economy, culture, education and others. In the first period after the war, the administration of the educational activity was taken over by Kosovo Interim Government, together with 
administration bodies, temporary as well, of the Security Council, known by the acronym UNMIK. Such a structure mixed with internationals and locals hard to adjust the criteria, norms and standards, moreover when it lacked basic element, the legal infrastructure. Although the system of education here, despite systematic and social, political, economic and legal refractions, it had preserved at least something from an experience of instituted empirical development and had the necessary professional potential for teaching, the infrastructure was almost totally ruined.

At the scene of organization, there came the so-called Applicable Laws, which in fact were nothing but an amalgam of different elements of systems full of contradictions. Therefore it was not strange that, for example, being two co-ministers of education (one local and the other international), despite their professional level, contests would start about competencies. Such a fate, to say tragicomic, was also faced by common Primer for all Albanian-speaking areas, which was "victimized" for several years, due to introduction of discrepancies of co-administrating concepts.

In a few words, this was the situation in the field of education, almost until the declaration of Kosovo as an independent state (17 February 2008). In such circumstances, two basic functions of education (vocational education and training), as preconditions of impact in the economic and social development of the country come too reduced.

In all this jumble, a large tribute is paid to the lack of planning, harmonization with social and economic development plans of the country. Thus, seen from an aspect there is a hyper-production of educated cadres, whereas on the other hand, there is no economic absorption capacity for such an enormous potential. As it rarely happens anywhere in the world, here they wander in vain, unemployed, even doctors and engineers, lawyers and economists, and many other professional profiles.

What can be considered innovation and bearing on this transitional period?

Innovations are not few. For the first time in the process of education in Kosovo, in the spirit of pluralism and democratization, depoliticizing of the education process happens, getting rid of ideology of teaching content, and above all the free competition.

Thus, besides public educational institutions, beginning with kindergartens, preschools and to the university, the private ones are allowed and are licensed as well.

Paradoxical phenomenon seems inevitable, that even in this area, light-shade structures appear. On one hand, as expected with reason, would be constructive competition and race for promotion of values and criteria in the field of knowledge, education and vocational training, in parallel with new achievements in the field of information technology; on the other side greed also found space for material gain thus degenerating this sensitive process as production of diplomas.

Treating here the aspect of the impact of education in development, in and during the transition, we ascertain that education impacts directly in two directions simultaneously, through the process of vocational education and training.

\section{General Education as a Concept of Personality}

When talking about education, usually this phenomenon comes as a syntagm, coupled with vocational education and training.

Why we can say so?

As it is generally known, all the sciences of knowledge define man as being social creatures, which, unlike the other living beings is characterized with consciousness and awareness, with the process of logical thinking. As such, the man undoubtedly is considered as one of the main resources of this planet. Depending on its psychophysical and social level, all the developments in society and in nature come, for better or worse.

The first task of education, educating is right here. In humanist profiling of human character. Moulding it with the right character and logical virtues, with knowledge and culture, with work habits, with a will to justice and progress, selfconfidence and sustainability in achieving the goals and progressive aspirations, basic preconditions are created for a complete personality.

In our circumstances, here in Kosovo, when we are dealing with a society of newly emerged from the war, experiences of survival furrows on the road to freedom, with frustrations in many areas with the absences of all kinds, I think it is necessary that in a move to turn to re-actualisation of values of enlightenment also in the field of education.

I remember as if it happened today, when I was an elementary school student, the Reading Book opened as usual with a text fragment, titled in vocative case Education! Never in life I heard within the spirit, with as much intensity, divine spirit with a breeze of spring. However, it was a text in prose which spontaneously was remembered just as rhythmic verses of a lyrical poem. I remember even now fragments of sentences. Then I didn't know anything about its author and imposition of its name, Rabindranat Tagore (1861 - 1941), not that it wasn't easy, but it seemed completely 
onomatopoeic. However, all figuration, tropes and metaphors of that text raised with light, sun, dawn of humanity, coolness, other rays coming through education.

Later on, I felt the same spirit of the verses of our men of the Renaissance, especially from Naim Frasheri (1846 1900 ) and onwards. Something refreshing and lighting being internally. I would have much time and readings to capture the meaning of the lighting phenomenon, illuminate. Now, even today, definition seems to me incomplete which is given in Wikipedia - the free encyclopaedia: "Enlightenment was a philosophical and cultural movement that spread to Europe from the beginning of $18^{\text {th }}$ century until French Revolution, which was carved by efforts of liberation through reason from thought, from insistence, imagination, prejudices and inherited ideologies of heritage of new and gained knowledge".

I consider it necessary to give on this occasion an interpretation of enlightenment notion, according to Prof. Dr. Masar Stavileci, according to the explanation in the introduction of his study including ". . . semantic process from lumiere revelee /discovered light or the light of god/ to lumiere de la raison emancipee / light of emancipated reason/. . ." (Stavileci, M. Age of Enlightenment in the Albanian National Renaissance Literature, Rilindja, Prishtina 1990, p. 11).

Being a movement with a focus mainly in formation in the Age of Enlightenment in $18^{\text {th }}$ century, for one thing, it would be completely anachronistic for our time, or the historical documentary value, with the development of cultural, artistic, social, moral and philosophic studies. I would probably suppose so if the study was not so serious as "The spirit of Enlightenment" from the essayist, historian, philosopher and theoretician of literature, Cvetan Todorov (Tzvetan Todorov 1939). Todorov, dealing with the interpretation of Memoars of the thinker of $18^{\text {th }}$ century, Condorcet, we will quote him in context of approval: "In general, any rule, of any kind of nature, in any hands to be given, in any way to be discussed by the nature, is an enemy of enlightenment" (Todorov. Tzvetan, The Spirit of Enlightenment, Buzuku, Prishtina 2009, p. 61).

So, why it happens this way?

The reason for this ascertainment looks simple: the more individuals are enlightened, the more are able to act independently and would be less inclined to submit to power in blind way. That is why, rightfully, Todorov insists: "Age of Enlightenment belongs to the past, since there has been a century it existed: however it cannot be considered as a past yet, because it is no longer a denominator of doctrine dated to history, but an attitude towards the world". (Ibid, page 111).

Based on that, today we hit colonialism, genocide, the reigning lovelessness, knowing that everlasting enemies of enlightenment are not only obscurantism, arbitrary authority, fanaticism and others. Todorov, spurred by the answer to the question from Kant: Are you experiencing a period of enlightenment, a really bright period? - No, but a period in process of lighting, proposes the phenomenon called Relighting of enlightenment.

Our opinion is that this transitional period in the field of education in our country needs this relighting. Personality moulded with this content is an irreplaceable effective in the development of the country in almost every area of action.

\section{Vocational Training on Contemporary Bases}

As stated above, that parallel with the process of education is also conceived the vocational training. That vocational training has unavoidable impact, not to say crucial role in the development of the country, such a thing as to be put into question and doubt. Although these two processes of education are almost entirely indivisible, vocational training has direct impact on development, in terms of immediate time. While the whole education process lies along all instances of education, vocational training has other grading.

Following this issue in detail, and based on personal experience in the field of education for several years, I can state that even in this plan, there have been, and there will be difficulties, in the platform, planning of legal reform, as well as on profiling structure of economic and social development of today's Kosovo.

When speaking of the period immediately after the war, the most sought cadres for work were language translators, and this phenomenon caused chaos in the learning process, in teaching, because it came out as professors and teachers of English language evaporated.

Meanwhile, seeing the direct and immediate benefit in the plan of material benefits, language courses opened in almost every village neighbourhood or within the city.

This disturbance of equilibrium parameters under the influence of the temporary circumstances did not pass without influence in the field of further development of the process of vocational training.

I think that impact of vocational training, respectively of education in economic and social development of a country has been rightly seen by Anemonë Zeneli, at an observation published by KIPRED:

"From the theoretical viewpoint, there are at least three mechanisms through which education may have an impact 
on economic growth.

Initially, the micro perspective, education increases essential human capital in the workforce, thus increasing labour productivity and thus will result in economic growth steadily towards a higher level of balance of production.

Secondly, education may increase the innovative capacity of the economy, as well as new knowledge about technology, the new products and processes that promote growth.

Thirdly, education can facilitate dissemination and transmission of knowledge required to understand the new information and for the successful implementation of new technology drafted by others, which again promote economic growth". (Anemonë Zeneli: KIPRED (Education Center), Role of education in the country's economic development, August 2013).

\section{Conclusion}

Being a small and a poor country, just coming out of a terrible war, with almost entire destruction of educational infrastructure, another paradox appears. Similar to some sectors of the economy, as well as in the field of business, for example in trading of petroleum products, when disloyal and unfair competition squeeze even ourselves, even in educational plan of vocational training, this obstructing phenomenon appears. If we consider the fact that in a country with a population of approximately two million, number of students in figures between 30 to 50 thousand and add this figure even twice or more of young scholars in elementary and high school education (see, Accreditation Agency of Kosovo: http: //www. akreditimi-ks. org), it appears that with this resource, we could not even turn out to have balanced the countries with much more advanced economy than ours.

Hence, to achieve the appropriate harmonization of right between needs, demands and offers; to have tangible effects in the development of the country, a series of measures by institutional structures are required, first by the Ministry of Education, Science and Technology, such as:

- Careful planning,

- Ongoing reform of educational process,

- Short-term and long-term investments,

- The cooperation with similar international organizations etc.

However, the human potential is a promising prerequisite, moreover when it is known that Kosovo, according to the percentage of the population in Europe, holds the main place regarding the number of young people. 